\title{
LA SENTENCIA DEL TRIBUNAL CONSTITUCIONAL 72/2005, DE 4 DE ABRIL, EN MATERIA DE LIBERTAD DE ENTRADA Y RESIDENCIA DE LOS EXTRANJEROS EN ESPAÑA
}

\author{
CAMINO VIDAL FUEYO \\ Profesora Titular de Derecho Constitucional \\ Universidad de Burgos
}

SUMARIO:

I. Introducción. los problemas de interpretación del art. 13.1 CE.

II. La sentencia del Tribunal Constitucional $72 / 2005$, de 4 de abril.

III. La jurisprudencia constitucional en materia de entrada, circulación y residencia de extranjeros en españa hasta la STC $72 / 2005$, de 4 de abril.

IV. Una interpretación alternativa del art. 13.1 CE.

\section{INTRODUCCIÓN. LOS PROBLEMAS DE INTERPRETACIÓN DEL ART. 13.1 DE LA CONSTITUCIÓN}

La aproximación doctrinal y jurisprudencial al art. 13.1 de la Constitución (CE) se ha hecho, a partir de la entrada en vigor de nuestra Norma Suprema y hasta nuestros días, desde diversas interpretaciones que, sin embargo, parten de la misma premisa: la consideración de que dicho precepto es vital para la configuración del régimen jurídico-constitucional de los derechos fundamentales de los extranjeros en España. Tal punto de partida no deja de ser lógico, pues se trata del único artículo del texto constitucional que se refiere expresamente a los extranjeros y que, además, está incluido en el Título primero, que lleva el rótulo "De los Derechos y Deberes Fun- 
damentales" y dentro de su Capítulo primero titulado: "De los españoles y los extranjeros ${ }^{1}$.

Sin embargo, y hasta la fecha, no se puede hablar de una interpretación clara y unívoca del Tribunal Constitucional (TC) en este sentido, pues son muchos los interrogantes que aún no han encontrado respuesta. El primero de ellos se refiere a la expresión libertades públicas: ¿̇se trata un término sinónimo al de derechos fundamentales o, por el contrario, el constituyente ha utilizado este enunciado con la intención de indicar algo distinto?, ¿qué valor otorga el art. 13.1 CE a los tratados internacionales?, ¿̇cuál es, exactamente, el objeto de la reserva de ley con que finaliza su primer apartado?, ¿qué añade esta reserva a la establecida, con carácter general, en el art. 53.1 CE?, ¿estamos ante una remisión para determinar el modo y condiciones con que los extranjeros han de ejercitar todos los derechos fundamentales que el Título I les reconoce o, por el contrario, se trata de una cláusula de habilitación que faculta a la ley y al tratado a expandir a los extranjeros - desde una plena libertad de configuraciónaquellos derechos que la Constitución no les reconoce expresamente, pero de cuyo ejercicio tampoco les excluye?

La jurisprudencia constitucional ha ido fijando algunas pautas de interpretación a partir de la STC 107/84, atribuyendo al legislador un papel cualitativamente relevante en la configuración del régimen de derechos fundamentales de los extranjeros y formulando la ya clásica división tripartita de los mismos basándose en un criterio material como el de la dignidad humana $^{2}$. No obstante, y al día de hoy, carecemos de una interpretación constitucional cerrada del régimen de derechos fundamentales de los extranjeros en España y, si se me permite, la STC 72/05 añade más confusión a la que ya existía.

Así, y como se intentará exponer a continuación, la última sentencia del Tribunal Constitucional en materia de entrada, residencia y libre circulación de extranjeros (STC 72/05) resulta, cuando menos sorprendente, por dos razones: se aparta de la jurisprudencia dictada sobre esta materia a partir de la STC 94/93, y lleva a cabo una interpretación del art. 13.1 CE radicalmente distinta a la sostenida por el Tribunal desde el año 1983.

$1 \mathrm{El}$ art. 13.1 CE establece: “Los extranjeros gozarán en España de las libertades públicas que garantiza el presente Titulo en los términos que establezcan los tratados y la ley".

2 Un análisis de la jurisprudencia del TC sobre esta materia en AJA, E., "Veinte Años de doctrina del Tribunal Constitucional sobre los derechos de los inmigrntes", La democracia constituciona (Estudios en homenaje al prf. F. Rubio Llorente), Congreso de los Diputados, TC, CEPC y otros, 2002, pp. 439 y ss. 


\section{LA SENTENCIA DEL TRIBUNAL CONSTITUCIONAL 72/05, DE 4 DE ABRIL}

\section{II.1. ANTECEDENTES.}

La sentencia trae causa de un recurso interpuesto por un ciudadano marroquí que pretendió entrar por el Puesto Fronterizo del Puerto de Almería procedente de Nador (Marruecos) en agosto de 2000, cuando era aplicable la Ley Orgánica (LO) 4/2000, de 11 de enero, sobre derechos y libertades de los extranjeros en España y su integración social (antes de la reforma llevada a cabo por la LO 8/2000, de 22 de diciembre). Dicha normativa exigía, en síntesis, como requisito para entrar en España, la presentación de pasaporte y de visado, aunque el visado podía ser sustituido por una autorización de residencia o documento análogo.

Formalmente el extranjero recurrente cumplía los requisitos legales para entrar en España: pasaporte en vigor y autorización de residencia otorgado por la Subdelegación del Gobierno en Tarragona el 5 de junio de 2000, de acuerdo con el procedimiento previsto para la regularización de extranjeros que se encontrasen en España de forma continuada desde antes del 1 de junio de 1999. Sin embargo, los funcionarios del Puesto Fronterizo consideraron que dicho permiso de residencia había sido obtenido de forma fraudulenta, a través de otra persona, al no constar en el pasaporte que el ciudadano extranjero hubiera estado en ningún momento en España (circunstancia que él mismo reconoció una vez asistido de intérprete y abogada de oficio). En consecuencia, los funcionarios concluyen que el permiso no es válido y deniegan la entrada del extranjero en territorio español, ordenando su retorno a Marruecos.

La letrada del turno de oficio que asistió al recurrente en las actuaciones administrativas, interpuso recurso contencioso-administrativo por el procedimiento especial para la protección de los derechos fundamentales de la persona invocando la vulneración de varios derechos fundamentales, siendo entre todos ellos el único relevante a efectos del fallo (tanto de los tribunales ordinarios como del TC) la libertad de residencia (ex art. 19 CE) en relación con el art. 13.1 CE. El recurso fue desestimado en primera y segunda instancia con el argumento de que la cuestión determinante en el caso sería la consideración del permiso de residencia (obtenido por el procedimiento de la regularización) como válido o inválido, lo que constituye una cuestión de legalidad ordinaria sobre la que los órganos judiciales no pueden pronunciarse en el procedimiento especial promovido.

Posteriormente se recurre en amparo ante el TC, imputando directamente a la resolución administrativa que acordó la denegación de la entrada en el territorio español una vulneración de diversos derechos fundamentales, pero el grueso de la sentencia se centra en la alegada vulneración del art. 19 CE. Por ello, el Tribunal entra de lleno en el examen de este precepto a partir del fundamento jurídico $4{ }^{\circ} \mathrm{y}$, partiendo del carácter autónomo de los distintos derechos recogidos en el mismo, aísla dos que, en una aproximación prima facie, 
podrían haber sido conculcados al ciudadano extranjero recurrente en amparo: el derecho a entrar en España y la libertad de residencia.

\section{II.2. El PERMiso De RESIDENCIA COMO REQUisito PARA EJERCER UN DERECHO LEGAL PERO NO FUNDAMENTAL, SEGÚN EL TC}

Las primeras afirmaciones de nuestro Interprete Supremo que interesa señalar, en relación con la supuesta violación del derecho a la libertad de residencia del recurrente son las siguientes:

"El extranjero que — como el ahora recurrente en amparo- no ha estado nunca en España, no puede invocar la libertad de residencia —el derecho a elegir el lugar o lugares donde se desea residir transitoria o permanentemente en territorio español- para amparar una conducta que se sitúa en el ámbito definido por el tipo de un derecho distinto: el de entrar en el territorio nacional. (...). Mientras no se haya entrado en España no es posible ejercer el derecho a elegir en ella el lugar de residencia, ni, por tanto, cabe aceptar que los eventuales impedimentos u obstáculos del poder público a las pretensiones del extranjero constituyan vulneraciones de la libertad de residencia garantizada por el art. 19 CE».

En todo caso, apostilla el TC, aún pudiendo obtenerse un permiso de residencia sin haber estado nunca en España "no se estaría en presencia de un derecho de libertad de residencia ex art. $19 \mathrm{CE}$, sino de una simple autorización administrativa o, todo lo más, de ejercicio de un derecho legal y no constitucional".

Estas afirmaciones son lo suficientemente importantes como para hacer un primer comentario en un doble sentido:

En primer lugar, no cabe duda que los derechos a "entrar" y "residir" en España tienen un contenido distinto, pero su posible interrelación se acentúa cuando de lo que se está hablando es de la hipotética extensión de su titularidad (previa intervención del legislador) a favor de los extranjeros. En el caso que analizamos, el extranjero recurrente no puede entrar en España si no tiene un permiso de residencia y, correlativamente, una vez que se encuentra en España sólo puede ejercer el derecho a la libertad de residencia si ha atravesado legalmente nuestras fronteras. Por eso no parece del todo improcedente invocar un supuesto derecho a la libertad de residencia derivado de la posesión de una autorización administrativa que, a su vez, es conditio sine qua non para poder atravesar legalmente la frontera española de acuerdo con la legislación vigente. De hecho, al extranjero recurrente se le deniega la entrada porque los funcionarios de frontera consideran que el permiso de residencia no es válido.

En segundo lugar, en este pronunciamiento el TC considera que contar con un permiso de residencia no implica estar en posesión de "un derecho de libertad de residencia ex art. 19 CE», sino de una simple autorización administrativa y, en consecuencia, ante el ejercicio de un derecho legal y no constitucional. Afirmación ésta que llama poderosamente la atención, pues se separa 
radicalmente de la jurisprudencia de este Tribunal asentada a partir de las SSTC 94/93, 116/93 y 242/94 donde se declara:

"los extranjeros que por disposición de una ley o de un tratado, o por autorización concedida por una autoridad competente, tienen derecho a residir en España, gozan de la protección que brinda el artículo 19 CE, aún cuando no sea necesariamente en idénticos términos que los españoles, sino en los que determinen las leyes y los tratados a los que se remite el art. 13 CE” (STC 94/93).

De dicha jurisprudencia se deduce que un permiso de residencia (es decir, una mera autorización administrativa) es la llave que abre al extranjero la puerta de la titularidad y, por tanto, de las garantías constitucionales con las que cuentan los derechos del art. $19 \mathrm{CE}$, siempre que cumpla el resto de requisitos que la Ley exige para hacerlo efectivo y dentro de los términos fijados por la misma. En otras palabras, el TC en una jurisprudencia que se consideraba consolidada, ha venido sosteniendo que una vez que se reúnen los requisitos legales para residir en España (y mientras se mantenga dicha situación de legalidad), el extranjero no se mueve en el plano de la mera legalidad, sino que goza de la protección del art.19 $\mathrm{CE}^{3}$.

De ahí la perplejidad que suscita la STC 72/05, que nos ocupa, pues sin hacer ninguna referencia al cambio en la línea jurisprudencial que se acaba de señalar, sitúa el problema en el terreno de la legalidad, lo que en última instancia va a ser el argumento de fondo que justifica la denegación de amparo del recurrente al concluir que se trata de una materia "ajena a la jurisdicción del Tribunal Constitucional" (FJ 8. ${ }^{\circ}$ ). La perplejidad aumenta cuando se comprueba que nuestro Alto Tribunal dedica cinco fundamentos jurídicos al examen de una cuestión que considera de mera legalidad.

\section{II.3. LA EXCLUSIÓN DEL DERECHO DE ENTRADA DE LOS EXTRANJEROS DEL ÁMBITO DEL ART. 13.1 CE}

Una vez que nuestro Tribunal Constitucional establece que lo único que podría otorgar un permiso de residencia es un derecho legal, aborda (en el FJ 5..$\left.^{\circ}\right)$ la cuestión previa de si existe un derecho fundamental de los extranjeros a entrar en España. En este sentido lleva a cabo una interpretación sistemática del art. 19 CE a la luz del art. 13.1 CE. De éste último precepto afirma lo siguiente:

A) «no se refiere a la totalidad de los derechos de los extranjeros, sino sólo a derechos fundamentales".

B) "dentro de éstos no recoge todos sus derechos fundamentales sino principalmente aquellos que, previstos para los españoles — los del art. 19, 23, etc.-

3 Diversos estudios que abordan el problema de la titularidad de los derechos recogidos en el art. 19 CE por parte de los extranjeros en: POMED SANCHEZ, L., Y VELASCO CABALLERO, F. (Eds.), Ciudadanía e Inmigración, Gobierno de Aragón, Zaragoza, 2003. 
, el art. 13 CE extiende a los extranjeros en España, pues buena parte de los demás — derecho a la vida, libertad religiosa, libertad personal, tutela judicial efectiva, etc. - corresponden a aquellos sin necesidad de la extensión que opera el art. 13.1 CE, es decir, sin necesidad de tratado o Ley que lo establezca".

Interpretación que le sirve de argumento para concluir, sin más explicaciones, que «el sujeto de derechos al que se refiere la regulación del art. 13.1 CE no es el extranjero sin más, sino el extranjero en España, el que ya ha entrado en nuestro país" (FJ 6. ${ }^{\circ}$ y, por tanto, "es claro, pues, que la literalidad del art. 13.1 CE, sin ninguna ambigüedad, no incluye el derecho a entrar en España como derecho fundamental de los extranjeros" (FJ 6. ${ }^{\circ}$ ).

Tanto esta última y taxativa afirmación, como la interpretación que del art. 13.1 CE hace el Tribunal en este pronunciamiento, rompen de nuevo con la línea jurisprudencial precedente (aunque el Tribunal tampoco alude a este supuesto cambio interpretativo), por lo que también merecen cierto detenimiento.

En mi opinión, es cierto que el art. 13.1 no incluye desde un punto de vista literal el derecho a entrar en España de los extranjeros, porque textualmente no incluye ningún derecho en concreto. Simplemente fija que los extranjeros gozarán en España de las libertades públicas que garantiza el Título primero en los términos que establezcan los tratados y la ley y la propia interpretación del término libertades públicas ha planteado serios problemas al Tribunal Constitucional.

Problemas que derivan de la inexistencia de una definición constitucional de libertades públicas, incluso de una mera precisión indirecta que pueda permitir una deducción a partir de criterios tácitos suministrados por el texto. En la STC 115/87, de 7 de julio, que es una de las más emblemáticas en materia de extranjería, la mayoría del Tribunal identifica este término con el de derechos fundamentales en sentido amplio. Sin embargo, esta sentencia cuenta con un importante voto particular firmado por los Magistrados Francisco Rubio Llorente, Francisco Tomás y Valiente, y Fernando García Mon para quienes cuando el art.13.1 CE emplea la locución libertades públicas está excluyendo expresamente la de derechos fundamentales. Según esta última lectura las consecuencias son claras: por un lado, los extranjeros gozarán de los derechos fundamentales enunciados en términos genéricos por la Constitución pero, por otro, y aquí radica la peculiaridad del voto particular, las libertades públicas (que van a constituir una categoría distinta a la de derechos fundamentales) podrán ser configuradas, cuando de extranjeros se trate y en virtud del tenor literal del art.13.1 CE, del modo en que el legislador crea oportuno, es decir, no tendrán para los extranjeros más contenido que el que establezca la ley o los tratados.

De manera que la interpretación literal y sistemática del art. 13.1 CE es complicada y es objeto de controversia doctrinal y jurisprudencial desde hace años, por eso llama la atención que la afirmación del TC en la sentencia 72/05 (dando por hecho que el art. 13.1 sólo se refiere a aquellos derechos fundamentales que, previstos para los españoles — los del art. 19, 23, etc.- - se po- 
drían extender a los extranjeros en España, salvo el derecho de entrada), no esté avalada por ninguna argumentación jurídica más allá de una supuesta (y discutible) interpretación literal.

A falta de una fundamentación jurídica distinta de la meramente textual, yo sólo me atrevería a afirmar que la única exclusión de derechos a los extranjeros que literalmente hace la Constitución se encuentra en el art. 13.2 CE y es respecto a los derechos del art. $23 \mathrm{CE}^{4}$. Por el contrario, lo que resulta más relevante es la remisión expresa que el art. 13.1 CE hace a las leyes y a los tratados, lo que se podría interpretar como un intento por establecer un cauce jurídico para extender a los extranjeros la titularidad de determinados derechos fundamentales que, como los del art. $19 \mathrm{CE}$, no nacen ex constitutione directamente a favor de los no nacionales, pero tampoco les están expresamente vedados como los del 23.

De hecho ésta parece ser la interpretación que apunta, aunque muy tímidamente y sin argumentos de fondo, el TC en el párrafo anteriormente reproducido, pero se contradice con la exclusión a priori del derecho de entrada, con la consideración del derecho de libertad de residencia de los extranjeros como un derecho meramente legal, y con la referencia al art. 23 como ejemplo de derechos que la ley puede extender a los extranjeros, porque: ¿qué derechos, entonces, son los que extiende el 13.1 si el Tribunal excluye la mayor parte del contenido del 19 y el propio 13.2 excluye los del 23 con las salvedades que fija en este segundo apartado?, ¿cuál es el exacto elenco de derechos fundamentales que, según el TC en este pronunciamiento, corresponden a los extranjeros sin necesidad de la extensión que opera el art. 13.1 CE, es decir, sin necesidad de tratado o ley que lo establezca?

En definitiva, se detecta un cambio en la línea jurisprudencial pero los grandes interrogantes respecto del régimen jurídico-constitucional de los derechos fundamentales de los extranjeros en España siguen sin respuesta.

\section{LA JURISPRUDENCIA CONSTITUCIONAL EN MATERIA DE ENTRADA, CIRCULACIÓN Y RESIDENCIA DE EXTRANJEROS EN ESPAÑA HASTA LA STC 72/05}

No son muchas las sentencias constitucionales que resuelven recursos de amparo interpuestos por un extranjero por presunta violación de los derechos recogidos en el art. $19 \mathrm{CE}$. El primero de estos pronunciamientos se dictó en marzo de 1993 por lo que estamos ante una jurisprudencia constitucional que, además de escasa, es relativamente reciente.

Esta falta de jurisprudencia tiene su causa en que hasta marzo de 1993, el Tribunal Constitucional no admitió, por improcedentes, ninguno de los recursos

$4 \mathrm{El}$ art. 13.2 reza: “Solamente los españoles serán titulares de los derechos recogidos en el art. 23, salvo lo que, atendiendo a criterios de reciprocidad, pueda establecerse por tratado o ley para el derecho de sufragio activo y pasivo en las elecciones municipales". 
de amparo interpuestos por extranjeros cuyas pretensiones se centraban en la vulneración de los derechos reconocidos en el art. 19 CE. Valga por todos, pues se utiliza la misma argumentación, el fundamento jurídico tercero del Auto 182/85, de 13 de marzo, donde se declara, en relación con el art. 19 CE:

«tal precepto no puede servir de apoyo para fundamentar las pretensiones del recurrente; pues lo que se establece en el mencionado precepto constitucional no es sino el derecho de los españoles a elegir libremente su residencia y a circular libremente por el territorio nacional, así como a entrar y salir libremente de España en los términos legalmente previstos".

Esta inicial línea jurisprudencial, opuesta a la seguida por el Tribunal Supremo $^{5}$, tiene también reflejo en el Fundamento jurídico tercero de la STC 99/85, de 30 de septiembre, en donde con motivo de la interpretación del artículo $13 \mathrm{CE}$, el Tribunal afirma:

"el disfrute por los extranjeros de los derechos y libertades reconocido en el Título I de la Constitución (y que por consiguiente se le reconoce también a ellos en principio, con las salvedades concernientes a los artículos 19, 23, y 29, como se desprende de su tenor literal, y del mismo art. 13 en su párrafo segundo), podrá atemperarse en cuanto a su contenido a lo que determinen los tratados internacionales y la ley española".

De manera que, durante más de una década, nuestro Tribunal Constitucional se mostró reacio a la extensión de la titularidad de las libertades reconocidas en el art. $19 \mathrm{CE}$ a favor de los extranjeros, basándose en una interpretación literal del artículo 19 CE que se refiere expresamente a los españoles. Es más, resulta significativo que la STC 99/85 (en el párrafo que se acaba de reproducir) coloque en el mismo plano de inaccesibilidad para los extranjeros, tanto los derechos de participación política y de acceso a las funciones y cargos públicos regulados en el art. $23 \mathrm{CE}$ (que aparecen expresamente prohibidos para los no nacionales en el art. 13.2 CE), como los derechos recogidos en el art. $19 \mathrm{CE}$. Sin embargo, a partir de 1993 se produce un importante cambio de jurisprudencia.

Las sentencias que abren esta nueva línea interpretativa (SSTC 94/93, 116/93 y 242/94) resuelven recursos interpuestos por razón de expulsión del territorio español y, puesto que la decisión de expulsar a un extranjero del territorio nacional afecta directamente a las libertades de circulación y residencia que contempla el art. $19 \mathrm{CE}$, la resolución de estos tres recursos plantea la cuestión previa de si un extranjero puede ser considerado titular de dichas libertades y, en su caso, con qué alcance.

El problema es resuelto de forma favorable, pues el Tribunal no sólo admite a trámite los recursos, sino que los estima y declara nulas las resoluciones

5 Que a partir de las sentencias dictadas el 25 de junio de 1980 (Ar. 3344) y el 3 de julio del mismo año (Ar. 3404), reconoce los derechos fundamentales a desplazarse y a residir en nuestro país a los extranjeros que hayan entrado legalmente en España. 
administrativas de expulsión impugnadas en las dos primeras demandas, y la decisión judicial de expulsión que se impugna en la tercera, cambiando radicalmente los criterios interpretativos que en relación con la titularidad de los derechos contenido en el art. 19 CE había mantenido hasta entonces. La argumentación que utiliza el Tribunal es similar en los tres pronunciamientos.

En primer lugar, se hace alusión al tenor literal del precepto constitucional y se afirma, en relación con él, que la inexistencia de declaración constitucional que proclame directamente la libertad de circulación de las personas que no ostentan la nacionalidad española no es argumento bastante para considerar resuelto el problema. En este sentido, y siguiendo la misma argumentación que se utilizó en el fundamento jurídico tercero de la STC 107/84, de 23 de noviembre, para extender a los extranjeros la titularidad del derecho a la igualdad, el Tribunal sostiene:

"La dicción literal del art. $19 \mathrm{CE}$ es insuficiente porque este precepto no es el único que debe ser considerado; junto a él es preciso tener en cuenta otros preceptos que determinan la posición jurídica de los extranjeros en España, entre los que destaca el art. 13 CE. Su apartado primero dispone que los extranjeros gozan en España de las libertades públicas que garantiza el Título I de la Constitución, aún cuando sea en los términos que establezcan los tratados y la ley. Y el apartado 2 de este artículo 13 solamente reserva a los españoles la titularidad de los derechos reconocidos en el art. 23 CE (...). Por consiguiente, resulta claro que los extranjeros pueden ser titulares de los derechos fundamentales a residir y a desplazarse libremente que recoge la Constitución en su art. 19" (STC 94/93, FJ 2. ${ }^{\circ}$ ).

En segundo lugar, el Tribunal Constitucional se refiere al art. 13.1 CE como el precepto básico en orden a la extensión, a favor de los extranjeros, de los distintos derechos recogidos a lo largo del Título primero (de todos), lo que le lleva a retomar la doctrina expuesta en la STC 107/84, esto es, la división tripartita de los derechos fundamentales de los extranjeros, utilizando como criterio de clasificación la mayor o menor vinculación de los mismos a la dignidad humana:

"Cuestión distinta, sin embargo, es el alcance que despliega la protección constitucional a los desplazamientos de los extranjeros en España. La libertad de circulación a través de las fronteras del Estado y, el concomitante derecho a residir dentro de ellas, no son imprescindibles para la garantía de la dignidad humana (art. 10.1 CE y STC 107/84), ni por consiguiente pertenecen a todas las personas en cuanto tales al margen de su condición de ciudadano" (FJ 3. ${ }^{\circ}$.

Afirmación que le sirve para sostener, a continuación, la licitud de que leyes y tratados modulen el ejercicio de estos derechos en función de la nacionalidad de las personas, introduciendo tratamientos desiguales entre españoles y extranjeros "en lo que atañe a entrar y salir de España, y a residir en ella" (es importante constatar que el Tribunal coloca en el mismo plano el derecho a entrar y el derecho a residir una vez que se ha entrado legalmente), para concluir declarando que: 
"los extranjeros que por disposición de una ley o de un tratado, o por autorización concedida por una autoridad competente, tienen derecho a residir en España, gozan de la protección que brinda el artículo 19 CE» (STC 94/93).

En resumen, el Tribunal Constitucional vuelve a utilizar un criterio material, como es el de la mayor o menor vinculación con la dignidad de la persona, para elaborar una clasificación de los derechos fundamentales de los extranjeros y para justificar una mayor o menor intervención del legislador en la regulación de los mismos, cuestión que merece algún comentario, pues sin poner en duda el indiscutible fundamento axiológico, material por tanto, de los derechos fundamentales que nuestra Constitución consagra, elaborar una clasificación de los derecho fundamentales de los extranjeros según su mayor o menor vinculación con dicha dignidad parece extremadamente arriesgado, pues se desconsidera la labilidad del concepto "dignidad de la persona", que se convierte fácilmente en una idea "pre" y "meta" constitucional, que descansa en argumentos muy respetables desde la perspectiva ética, pero poco consistentes desde una perspectiva estrictamente jurídica. No son las percepciones subjetivas sobre lo que la "dignidad de la persona" sea las que pueden garantizar un ámbito de seguridad jurídica y excluir la arbitrariedad del intérprete, sino que lo que la "dignidad de la persona" sea, desde la óptica del derecho positivo es, sobre todo, lo que la Constitución dice que es a lo largo de todas sus normas. Y, en consecuencia, resulta arriesgado en extremo y notablemente arbitrario, cualquier gradación de los derechos fundamentales en función de su mayor o menor proximidad con las exigencias derivadas de tal dignidad ${ }^{6}$.

Pero, al margen de estas consideraciones, lo cierto es que el TC extiende la titularidad de los derechos fundamentales reconocidos en el art. 19 CE a los extranjeros que cumplen los requisitos legales. En esta tesitura estaríamos ante un tipo de derechos fundamentales respecto de los que la expresión configuración legal adquiere una especial relevancia.

Esta necesidad de que el extranjero se encuentre en situación legal, como condición necesaria para acceder a la titularidad de los derechos que nos ocupan, implica una cierta tautología, pues los extranjeros gozan de la titularidad de ciertos derechos fundamentales (categoría jurídica que por definición es especialmente resistente a la acción del legislador), solamente si cumplen los requisitos legalmente exigidos para entrar y permanecer en España. Es más, el Tribunal Constitucional habrá de comprobar, antes de dictar sentencia, si el extranjero cumple todos los requisitos que la ley exige para la entrada, y permanencia en España y sólo tras esta verificación podrá constatar si el extranjero recurrente es titular del derecho fundamental a entrar, a residir y a circular por el territorio español y, en su caso, si se ha producido una violación de dichos derechos.

6 Sobre el papel que desempeña la dignidad de la persona en el ordenamiento jurídico español y en la jurisprudencia del TC: GUTIERREZ GUTIERREZ, I., Dignidad de la persona y derechos fundamentales, Marcial Pons, 2005. 
Por todo ello, al TC no le queda más remedio que revisar el cumplimiento de la legalidad ordinaria por parte del extranjero, así como la adecuada aplicación de dicha legalidad por la Administración Pública, porque la misma es el origen inmediato y directo del acceso de los extranjeros a la titularidad de los derechos fundamentales del art. 19 CE.

En definitiva, esta es una línea jurisprudencial que parecía asentada en nuestro Tribunal Constitucional y de la que, sin embargo, tal y como se ha expuesto anteriormente, parece separarse la STC 72/05.

\section{UNA INTERPRETACIÓN ALTERNATIVA DEL ART. 13.1 CE}

Tal vez, las dificultades interpretativas que acabamos de resumir pueden superarse desde un enfoque distinto. A partir de la idea elemental de que un ordenamiento jurídico es un sistema en cuyo seno las normas carecen de existencia singular, de suerte que sólo adquieren sentido en función del "todo", debe acudirse necesariamente a una interpretación sistemática de la Constitución que ponga en relación cada precepto con el conjunto, y a una interpretación teleológica que incorpore al proceso hermenéutico los valores del ordenamiento.

Desde ese planteamiento, no es difícil llegar a la conclusión de que la titularidad subjetiva de los derechos fundamentales se extrae de cada uno de los preceptos constitucionales que los consagran, interpretados atendiendo no tanto a su tenor literal —aunque diste de ser irrelevante-como al conjunto de los valores constitucionales y a los contenidos de los tratados internacionales relativos a los derechos humanos ratificados por España, tal y como exige el art. 10.2 CE. De manera que la fuente de los derechos fundamentales está para los extranjeros, igual que para los españoles, no tanto en el art. 13.1 CE (como se desprende de la jurisprudencia constitucional en materia de extranjería hasta la sentencia que comentamos), sino en el conjunto del texto constitucional - particularmente en el Capítulo segundo del Título primero-. En consecuencia, habrá que buscar un sentido autónomo al art. 13.1 CE, que no conduzca al resultado del legislador redundante, ni vacíe de contenido el precepto.

Pues bien, si los extranjeros disfrutan en España de los derechos fundamentales que les reconocen los distintos preceptos del Capítulo segundo del Título primero, interpretados a la luz de los dispuesto en el art. 10.2 CE, el art. 13 $\mathrm{CE}$, en sus dos primeros apartados, no se refiere tanto a los derechos que los extranjeros tienen, como a los que no tienen.

La cláusula de "habilitación-expansión" en que el art. 13.1 CE consiste, faculta a la ley y al tratado a expandir a los extranjeros - desde una plena libertad de configuración-, aquellos derechos que la Constitución no les reconoce (derechos como la libertad de entrada y establecimiento), y el art. 13.2 CE completa el perfil de dicha habilitación prohibiendo que se "expandan" a los extranjeros los derechos reconocidos en el art. $23 \mathrm{CE}$, salvo el derecho al sufragio activo y pasivo en elecciones municipales, derecho éste que también 
podrá extenderse a los extranjeros mediante ley y tratado siempre que haya reciprocidad.

En definitiva, los apartados $1 .^{\circ}$ y $2 .^{\circ}$ del art. 13 CE nos están diciendo que hay determinados derechos fundamentales de los que los extranjeros no son titulares - pero no porque así lo establezca el art. $13 \mathrm{CE}$, sino porque así se desprende de los diversos preceptos constitucionales reconocedores de derechos, debidamente interpretados - pero que, con la excepción parcial de los derechos del art. $23 \mathrm{CE}$, podrán ser atribuidos a los extranjeros mediante tratado o la ley ${ }^{7}$.

Por ello, resulta coherente que, cuando la ratificación del Tratado de Maastricht obliga a una previa modificación de la Constitución para atribuir a los ciudadanos comunitarios el derecho de sufragio pasivo en las elecciones municipales, la reforma se haga por la vía del art. 167 CE y no por la del $168 \mathrm{CE}$, porque lo que se reformó no fue el art. $23 \mathrm{CE}$ sino el art. 13.2 CE, que recogía una excepción a la cláusula de expansión del art. 13.1 CE.

De suerte que, gracias al art. 13.1 CE, un derecho fundamental inicialmente no reconocido para los extranjeros se convierte, tras la mediación de la ley o del tratado, y en los términos que ellos establezcan, en derecho de los no nacionales. Estos derechos van a contar con la eficacia y la tutela propia de los derechos fundamentales pero, al ser disponibles para el legislador, se convierten en un buen ejemplo de la categoría derechos fundamentales de configuración legal.

El derecho a entrar en España de los ciudadanos comunitarios es un claro ejemplo de lo que estamos exponiendo. Se trata de un derecho que cuenta con todas las garantías constitucionales, pues nada impediría a un ciudadano comunitario recurrir en amparo una hipotética violación de este derecho que, sin embargo, no nace ex art. 19 CE - pues tal precepto sólo reconoce el derecho de entrada de los ciudadanos españoles-, sino del Tratado de la Unión Europea, en conexión con el art. 13.1 CE.

Lo mismo ocurre cuando un tratado internacional sectorial exime a los ciudadanos de un país determinado del requisito del permiso de trabajo para realizar en España actividades por cuenta ajena, equiparándolos, en ese sentido, a los ciudadanos españoles. Si, hipotéticamente, a dichos extranjeros se les sancionara por estar trabajando en España careciendo de permiso de trabajo, podrían invocar ante los tribunales ordinarios (utilizando el recurso preferente y sumario previsto en el art. 53.2 CE) la violación del derecho fundamental a la igualdad —el otro término de la comparación serían los españoles_-, e incluso, en su caso, recurrir en amparo ante el Tribunal Constitucional.

Con respecto a los derechos fundamentales que la Constitución no reconoce a los extranjeros - pero que tampoco les niega-, la ley o los tratados son libres, de acuerdo con la facultad que les otorga el art. 13.1 CE, para extenderlos a los extranjeros con las modulaciones que crea oportunas, otra cosa es que

7 Vid. VIDAL FUEYO, C., Constitución y Extranjería, Centro de Estudios Políticos y Constitucionales, 2002, pp. 303 y ss. 
una vez reconocidos gocen, por la acción expansiva del art. 13.1 CE, de todas las garantías constitucionales. En relación con este grupo de derechos, el legislador puede introducir diferencias no sólo entre españoles y extranjeros, sino también entre los propios extranjeros.

En conclusión, no se trata de buscar argumentos jurídicos para convertir en derecho fundamental la eventual expectativa de entrar en España de miles de millones de extranjeros que se encuentran en otros países, sino de analizar cuál es la posición jurídica del extranjero que estando en la frontera española y reuniendo todos los requisitos legales que la normativa española exige para poder entrar en nuestro país, se le deniega la entrada y es devuelto a su país.

Así, e independientemente de que en el caso concreto que hemos analizado el ciudadano recurrente en amparo tuviese o no derecho a entrar y residir en nuestro país (pues todo parece indicar que el permiso de residencia con el que contaba fue obtenido de forma fraudulenta), lo cierto es que tanto los tribunales ordinarios que conocieron del proceso especial para la protección de los derecho fundamentales de la persona, como el Tribunal Constitucional, no entraron a resolver la cuestión por considerarla de estricta legalidad, obviando el hecho de que el art.13.1 CE se remite no sólo a los tratados, sino también a la ley, cuando se refiere a los términos en que los extranjeros gozarán en España de las libertades públicas que garantiza el Título Primero.

ABSTRACT. The last judgment of the Spanish Constitutional Court in matter of entry, residence and freedom of movement of foreigners in Spain (STC 72/05) separates of the jurisprudence dictated on this subject from the STC 94/93 and, in addition, carries out an interpretation of the art. $13.1 \mathrm{CE}$ different from the supported one by the court since 1983. Nevertheless it does not solve the critical constitutional questions respect to the alien's fundamental rights in Spain. The article also offers an alternative interpretation of the art. $13.1 \mathrm{CE}$. 